\title{
Analysis on the Trend of Water Quality in Haihe River Basin from 2005 to 2017
}

\author{
Hongcui Wang, Daotan Wang, Xushen Zhou \\ Haihe River Water Conservancy Commission, Tianjin, China \\ Email: lalycui1981@126.com
}

How to cite this paper: Wang, H. C., Wang, D. T., \& Zhou, X. S. (2018). Analysis on the Trend of Water Quality in Haihe River Basin from 2005 to 2017. Journal of Geoscience and Environment Protection, 6, 1-7. https://doi.org/10.4236/gep.2018.611001

Received: October 20, 2018

Accepted: November 13, 2018

Published: November 16, 2018

\begin{abstract}
Haihe River is one of the 7 largest rivers in China. The problem of water pollution in Haihe River Basin is serious. The water quality of Haihe River Basin is generally the best in the north and the worst in the south. And the water quality of the Luanhe River is the best, the proportion of I - III is about $60 \%$, and the water quality of the Tuhaimajia River is the worst, the proportion of $>\mathrm{V}$ exceeds $60 \%$. According to the trend of water quality change, the improvement of Shandong Province in Tuhaimajia River system is the most obvious, and proportion of $>\mathrm{V}$ water decreased from $100 \%$ to about $30 \%$.
\end{abstract}

\section{Keywords}

Haihe River Basin, Water Quality, Change, Trend

\section{Introduction}

Haihe River is one of the 7 largest rivers in China. Collecting such 7 sub branches and plunging into the sea at Tianjin as Jiyun, Chaobai, Yongding, Daqing, Ziya and Zhangweinan. Together with other 2 neighboring rivers, the Luan river and Tuhaimajia river, they constitute the so called Haihe River Basin.

Haihe River Basin lies with Bohai Sea east, Yellow River south, Taihang Mountains west and Mongolia highland north, covers part or whole of Beijing and Tianjin city as well as such 5 provinces as Hebei, Shanxi, Henan, Shandong, Liaoning as well as Inner Mongolia Autonomous Regin, with a total area of $320,600 \mathrm{~km}^{2}$ and a total population of about 140 million.

Haihe River basin is temperate humid, semi-arid continental monsoon climate zone, annual average rainfall of $535 \mathrm{~mm}$, and there is obviously uneven distribution, average annual amount of 37 billion cubic meters of water, less than 270 cubic meters per capita water resources, only to the national average of 
$1 / 8$, is one of the most scarce water resources of the nation. The problem of water pollution in Haihe River Basin is serious, it has became the key constraints on social and economic sustainable development of the basin.

\section{Methods and Materials}

With the development of social economy and the dramatic impact of human activities, the Haihe River Basin is polluted seriously (Song, et al., 2012). And the water pollution situation in Basin is the most serious in the seven major river basins in the country ( $\mathrm{Li}$ et al., 2000). With the implementation of the most stringent water resources management system, the situation of water pollution in Haihe River basin has been gradually improved in recent years.

\subsection{Data Sources}

From 2005 to 2017, data such as the length of river, the percentage of different water quality categories in the river basin, the percentage of different water quality categories in each river system, and the percentage of water quality category in each region are obtained from "Haihe River Basin water resource bulletin" (HWCC, 2005-2017).

The total evaluated river length of Haihe River Basin basically is increasing year by year from 2005 to 2017, with a wider coverage and greater representativeness. And it is $11,808.1 \mathrm{~km}$ in $2005,12,679.8 \mathrm{~km}$ in 2010 and $15,324.6 \mathrm{~km}$ in 2017. The total estimated river length of the Haihe River Basin from 2005 to 2017 is shown in Figure 1.

\subsection{The Water Quality}

The evaluation of water quality in Haihe River Basin adopts "Environmental quality standard for surface water" (GB 3838-2002). The colors of different water quality categories are expressed according to "Technological regulations for surface water resources quality assessment" (SL 395-2007), that is, class I is blue, class II is green, class III is yellow, class IV is red, class V is purple, and class $>\mathrm{V}$ is black.

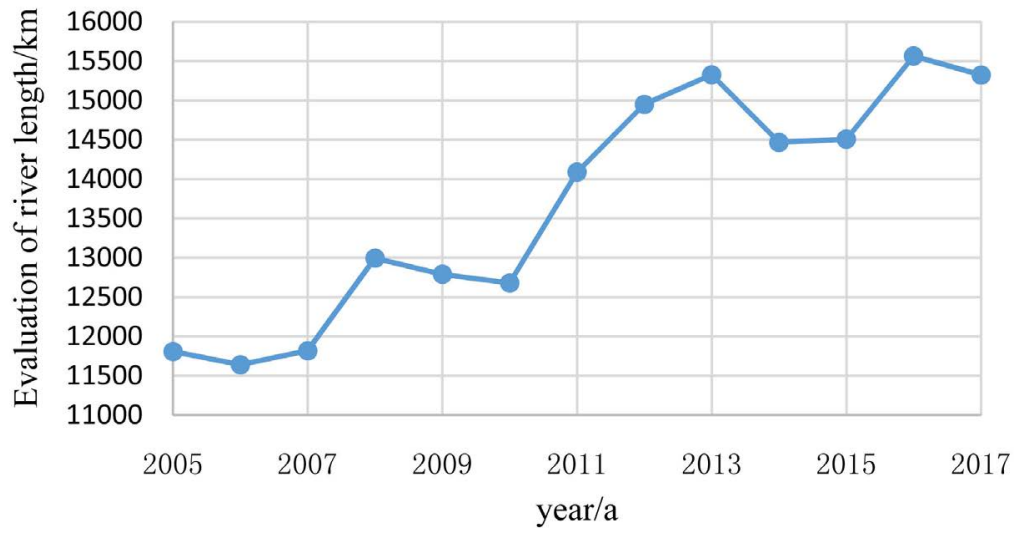

Figure 1. The total estimated river length of the Haihe River Basin from 2005 to 2017. 
According to the analysis of different water quality categories in 2005, 2010, 2015, 2017 in Haihe River Basin (Figure 2), it can be seen that the proportion of I III basically changed little, and the proportions of IV V were $6.1 \%, 14.6 \%, 20.0$ and $6.1 \%$ respectively, showing an obvious upward trend. The proportion of $>\mathrm{V}$ were $53.60 \%, 48.20 \%, 45.81 \%, 39.23 \%$, which showed an obvious downward trend. Based on the analysis of the percentages of different water quality types in the Haihe River Basin from 2005 to 2017 (Figure 3), it can be seen clearly that the proportion of $>\mathrm{V}$ is gradually decreasing, and the water environmental quality of the Haihe River Basin has shown a gradual improvement trend.

\section{Results and Discussion}

\subsection{The Water Quality of Different River}

According to the water system, the proportion of I - III, IV - V and $>$ V in Haihe
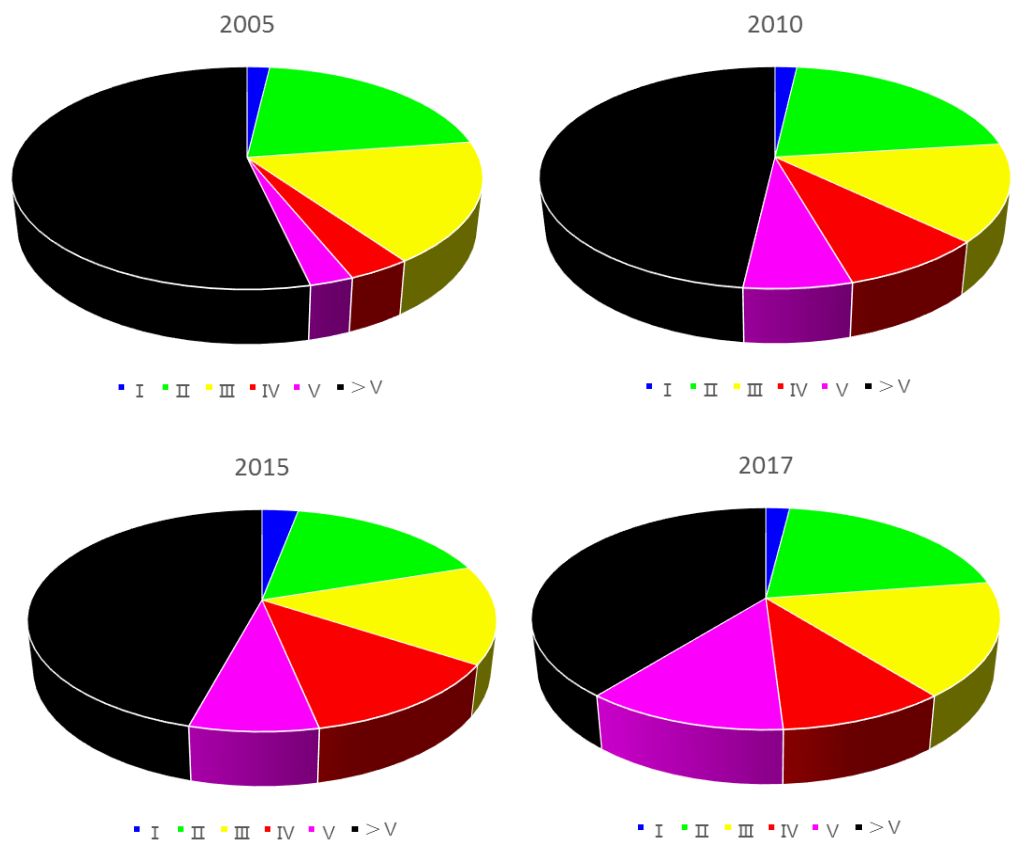

Figure 2. The proportions of water quality category of Basin in 2005, 2010, 2015 and 2017.

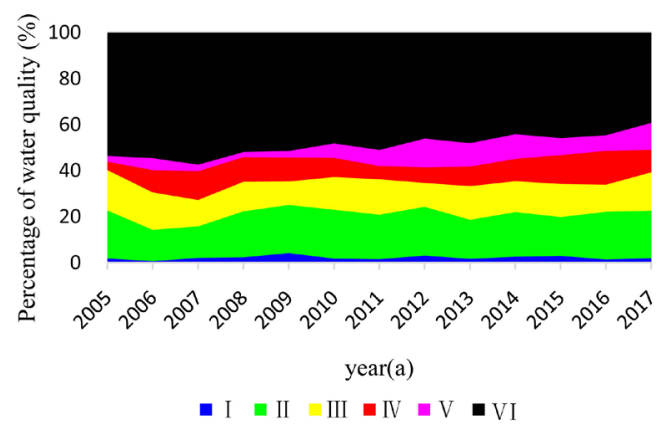

Figure 3. The proportions of water quality category of Basin from 2005 to 2017. 
River Basin was analyzed in 2005, 2010, 2015, 2017 (Figure 4). And I - III was expressed in blue, IV - V in red and $>\mathrm{V}$ in black. It can be seen from Figure 4 that the water quality of Luanhe River is the best, the water quality of I III accounts for more than $60 \%$, the water quality of North Haihe River is next, I III is about $40 \%$. And the water quality of South Haihe River is poor, I - III is $20 \%$ $30 \%,>\mathrm{V}$ is about $60 \%$, the Tuhaimajia River is the worst, with low proportion of I - III and high IV - >V.

Luanhe River water quality is the best, it shows a steady and slow improvement trend. The water environmental quality of Luanhe River from 2005 to 2017 is detailed in Figure 5 (LR). It can be seen that during 2005-2017, the proportion of I - III accounts for more than $60 \%$, and the highest is $75.4 \%$ in 2017 . The proportion of $>\mathrm{V}$ decreased from $20 \%$ to $9.2 \%$.

The water quality of North Haihe River is next, but the change of water quality is not obvious. The water quality of North Haihe River in 2005-2017 is detailed in Figure 5 (NHR). It can be seen that, in the period of 2005-2017, the proportion of I - III is between $34.0 \%$ and $49.4 \%$, little change; and the proportion of $>\mathrm{V}$ is floating up and down around $40 \%$, the difference is not obvious.

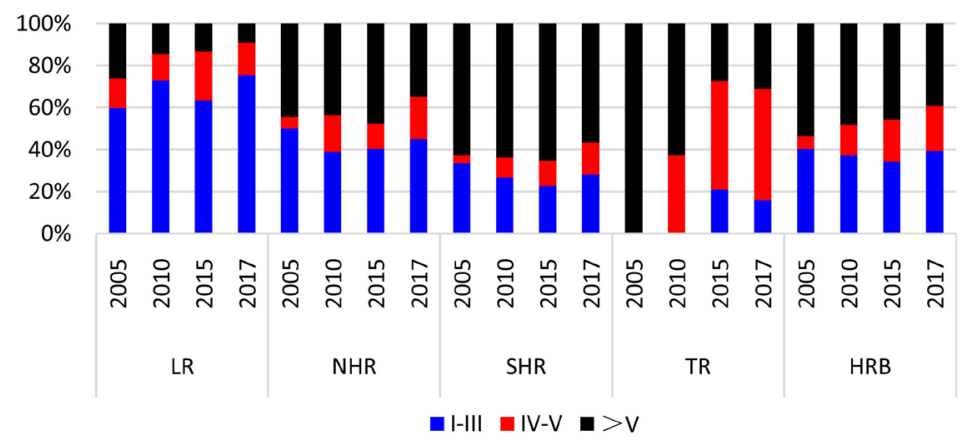

Figure 4. The proportions of water quality of different rivers in 2005, 2010, 2015 and 2017.

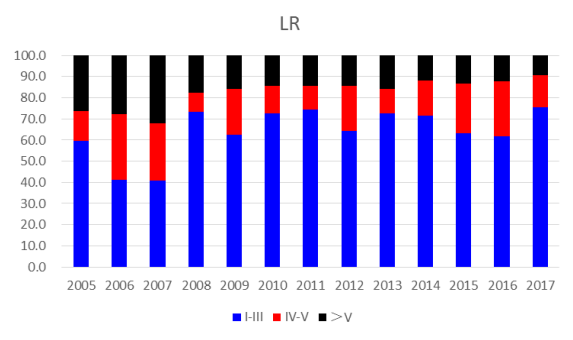

SHR

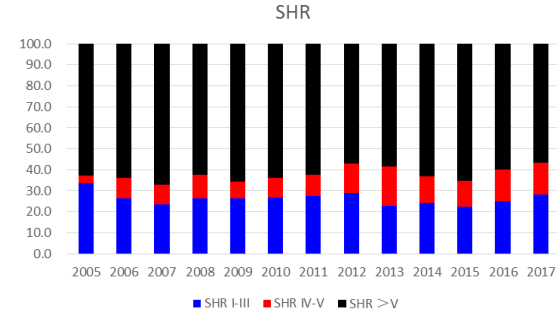

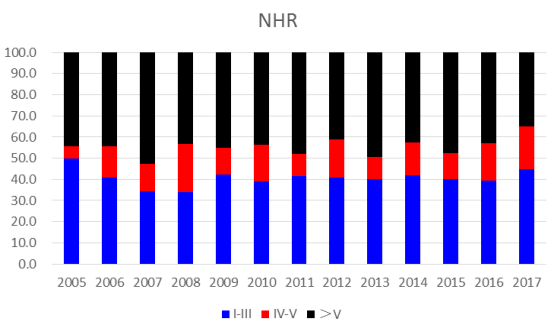

TR

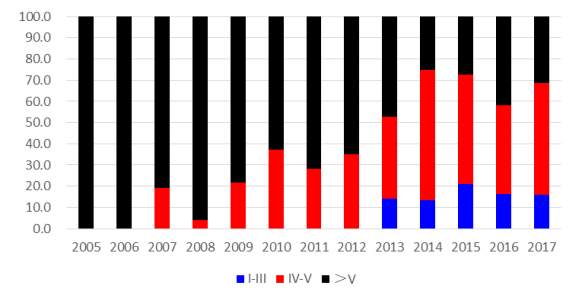

Figure 5. The proportions of water quality category of different rivers from 2005 to 2017. 
The water quality of South Haihe River is poor, and the water quality changes are not obvious. The water quality of SHR from 2005 to 2017 is shown in Figure 5 (SHR). It can be seen that during the period of 2005-2017, the proportion of I-III waters is between 22.5 and $33.5 \%$, with little change; and the proportion of $>\mathrm{V}$ is floating up and down around $60 \%$, the difference is also not obvious.

The water quality of Tuhaimajia River is the worst, but the improvement of the water quality is obvious. The water quality of TR in 2005-2017 is shown in Figure 5 (TR). It can be seen that during the period of 2005-2017, the proportion of $>\mathrm{V}$ was gradually reduced from $100 \%$ to $60 \%-70 \%$, and now only $30 \%$, the water quality has improved significantly.

\subsection{The Water Quality of Different Region}

According to the administrative region, the proportion of I-III, IV-V and $>\mathrm{V}$ in Haihe River Basin was analyzed in 2005, 2010, 2015, 2017 (Figure 6). It can be seen from Figure 6 that the water quality of Beijing and Neimenggu is the best, the water quality of I - III accounts for more than 70\%, the water quality of Hebei is next, I-III is about 50\%. And the water quality of Tianjin, Shanxi, and Shandong is poor; the Henan is the worst, there is almost no I - III, but all IV - >V in recent years.

The water quality of haihe river basin from 2005 to 2017 is shown in Figure 7. It can be seen that the water quality in Beijing, Tianjin and Hebei is not significantly changed, the water quality in Shandong and Shanxi is significantly improved, but the water quality in Henan, Neimenggu shows a downward trend. From Figure 7 (SD) can be seen that although the Shandong water quality is poorer, but the trend of water quality improvement is very obvious, during the period 2005-2017, the proportion of $>\mathrm{V}$ was gradually reduced from $100 \%$ to $50 \%$, and now only 30\%. From Figure 7 (SX), it can be seen that Shanxi's $>$ V water drops from about $70 \%$ to $29.4 \%$. It can be seen from Figure 7 (HN) that the quality of Henan has shown a downward trend, I-III has dropped from about $20 \%$ to $10 \%$, and even no I-III. From Figure 7 (NMG) can be seen, although Neimenggu has a good water quality, it also shows a downward trend. From 2008 to 2011 , I-III water is $100 \%$, but currently only accounts for about $70 \%$.

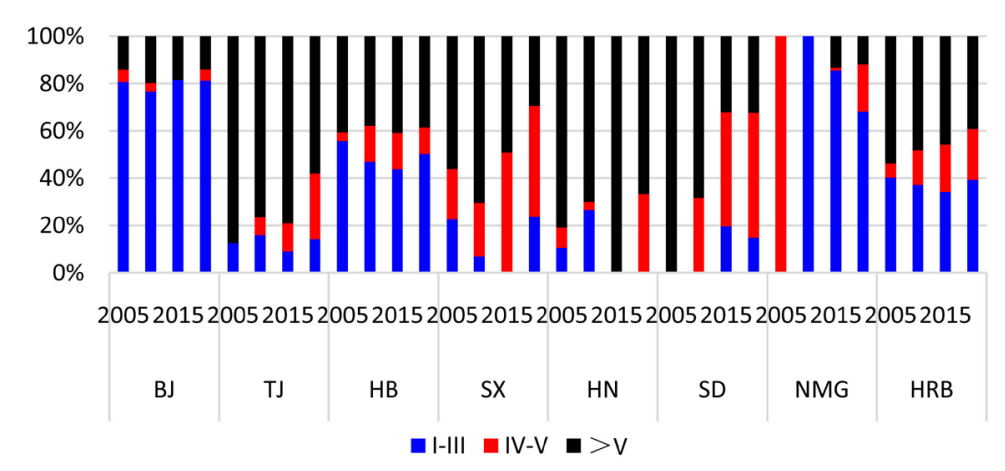

Figure 6. The proportions of water qualityof different regions in 2005, 2010, 2015 and 2017. 

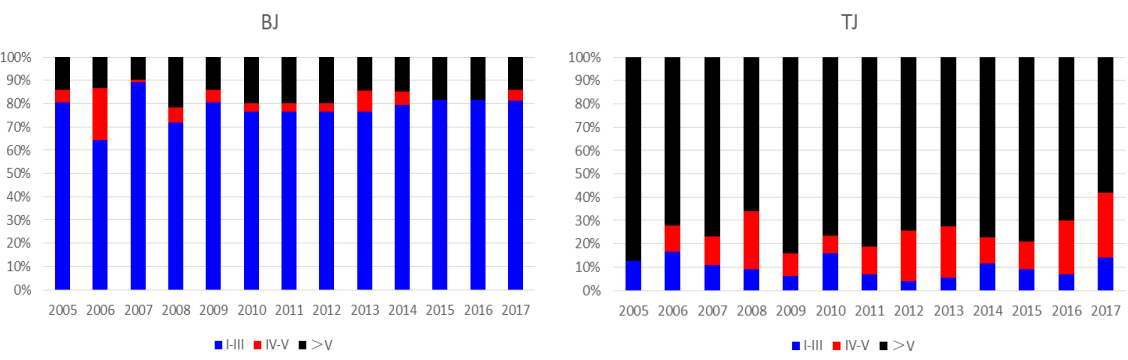

$\mathrm{HB}$

SD
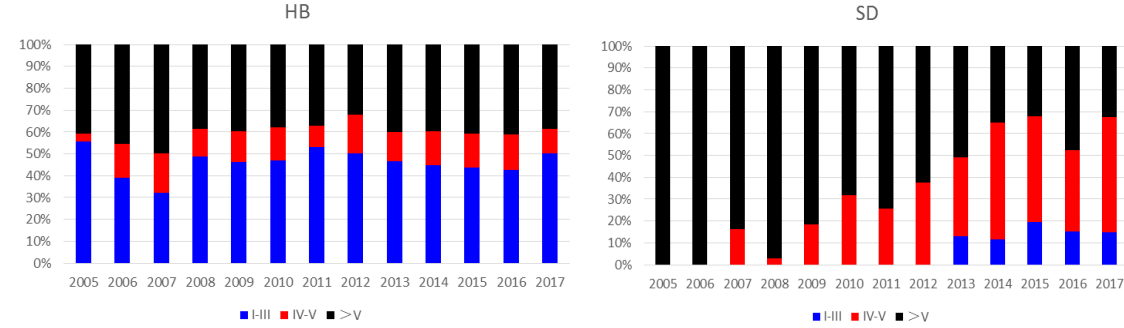

SX

$\mathrm{HN}$
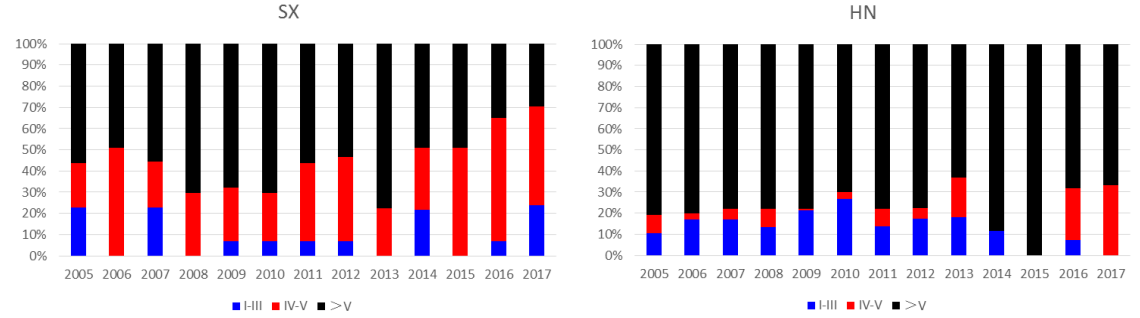

NMG

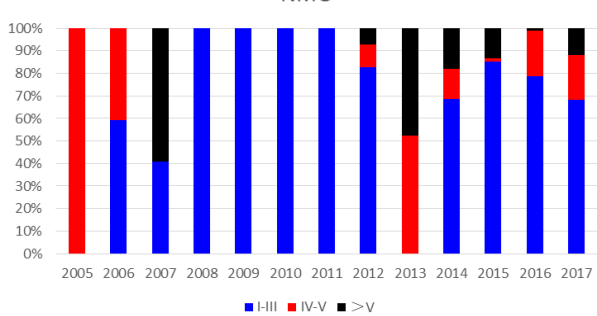

Figure 7. The proportions of water quality category of different regions from 2005 to 2017.

\section{Conclusion}

The water quality of Haihe River Basin is serious, generally the best in the north and the worst in the south. And the water quality of the Luanhe river and North Haihe River is better, the proportion of I - III is about $40-60 \%$, and the water quality of Sorth Haihe River and Tuhaimajia river is worse, the proportion of $>$ Vexceeds $60 \%$. According to the trend of water quality change, the improvement of Shandong Province in Tuhaimajia river system is the most obvious, and proportion of $>\mathrm{V}$ water decreased from $100 \%$ to about $30 \%$.

\section{Conflicts of Interest}

The authors declare no conflicts of interest regarding the publication of this paper. 


\section{References}

HWCC Haihe River Water Resources Bulletin. (2005-2017). 1, 22.

Li, H. M., Huo, J. M., \& Yu, H. (2000). Comprehensive Assessment of Water Pollution and Water Quality for the Haihe River Basin. Water Resources Protection, 4, 12-14.

Song, X. X., Yan, H. W., \& Tian, B. H. (2012). Analysis of Pollution in Haihe River and Its Conventional Indicator. South-to-North Water Diversion and Water Science \& Technology, 10, 98-101. 